\title{
CUANDO TRES NO SON MULTITUD. PROGENITORES, PROCREADORES Y PROVEEDORES EN LA CONFORMACIÓN DE LAS NUEVAS TÉCNICAS REPRODUCTIVAS
}

When three are not a multitude. Biological parents, procreators and providers in the formation of new reproductive techniques

Elixabete Imaz *

* Universidad del País Vasco / Euskal Herriko Unibertsitatea elixabete.imaz@ehu.es

Algunas frases condensan tanto conocimiento común sobre el funcionamiento de nuestra cotidianidad que al escucharlas esbozamos una sonrisa. Es el caso de la expresión "tres es multitud" que sintetiza de forma eficaz el modelo procreativo de Occidente en el que dos y solo dos, uno y otra, liberados de la supervisión de terceros que se inmiscuyan sean estos Estado, comunidad, red de parentesco o iglesia (Lebrun y Burguière, 1988)- ejecutan el acto procreativo. Es en la intimidad, sinónimo de sexualidad, pero también de espacio físico del hogar, el hogar conyugal ("el casado casa quiere" es también un dicho que refiere a esta preferencia cultural) donde el proceso procreativo se desarrolla. Schneider (1980) plantea que el coito heterosexual condensa y simboliza el parentesco occidental en cuanto que aúna sexualidad y procreación, vínculo conyugal y filiación. El coito heterosexual, la sexualidad procreativa, produce y reproduce la familia. Es así que, tal y como apunta Weston (2003), quienes renuncian al coito heterosexual renuncian con ello a la procreación, a la familia y a la reproducción de la red de parentesco. Las personas que optan por la homosexualidad o el celibato estarian optando por la no-familia.

Por eso el ámbito íntimo, que es el ámbito de la sexualidad y de la familia, es necesariamente de dos y sus descendientes dependientes, descendientes que una vez adultos "abandonan el nido" — un término con 
el que los sociólogos de la familia denominan a la fase en la que los hijos dejan a la familia de origen para crear un nuevo "nido" de amor, intimidad y procreación (Parsons, 1977)-. Esta idea de la familia habitando un hogar, aislada del exterior que es el ámbito de la sexualidad y de la crianza, de la conyugalidad y de la parentalidad es según Segalen (1988) un componente ideológico de las sociedades burguesas que se asientan a partir del siglo $X I X$ y que adquiere "el peso normativo de un modelo familiar único, fuera del cual todo es desviación" (ibídem: 410).

\section{MODELO PROCREATIVO Y TÉCNICAS REPRODUCTIVAS}

La irrupción de las tecnologías reproducción asistida aplicadas en humanos (TRAs) ha tenido efectos desestabilizadores en este modelo procreativo y de familia a dos, es decir, en torno a la pareja heterosexual. En una primera fase por medio de mediadores biomédicos: la medicina desde hace ya casi dos siglos - véase Stolcke (2018) en este monográficomás que a curar se ha consagrado a subsanar las dificultades que algunas parejas heterosexuales tenían para cumplir con el modelo procreativo que establece la contigüidad entre sexualidad heterosexual, coito y familia.

En esta primera fase la díada heterosexual fue intervenida por el conocimiento experto, que comenzó a minar esa idea de intimidad aislada ${ }^{1}$ por medio de intervenciones que sustituían la concepción por coito por la inseminación artificial que, como procedimiento, puede convenirse, imitaba al coito heterosexual. Mucho más tarde, la fecundación in vitro, saca a la concepción de sus ámbitos originales: no solo la saca del ámbito simbólico de la intimidad conyugal sino que la saca del ámbito corporal mismo. Se quiebra la unidad entre sexualidad, conyugalidad heterosexual y procreación, se multiplican las opciones de intervención de terceros. Se convierte en una práctica de laboratorio donde es visible la ruptura: ya no hay contigüidad ni isomorfismo posible con la intimidad procreativa original.

\footnotetext{
${ }^{1}$ Podríamos probablemente establecer una coincidencia temporal entre la irrupción en la intimidad sexual-reproductiva de expertos médicos y la irrupción de otros conocimientos expertos en otras fases del proceso reproductivo como el embarazo y el parto o la crianza (Davis-Floyd, 1993; Morata Marco, 2004; Palacio Lis, 2003; Uribe, 2016), expertos que están interviniendo en la ficción de la familia como ámbito aislado.
} 


\section{LA DONACIÓN: TERCEROS EN DISCORDIA}

Pero es sobre todo la donación heteróloga ${ }^{2}$ la que hace quebrar el modelo procreativo. La donación de gametos, tanto como la gestación subrogada, rompen el modelo procreativo en el que las dos y solo las dos personas que contribuyen a la procreación son también aquellas que se encargarán de la crianza y ostentarán el título de progenitor o progenitora. Con la donación reproductiva las figuras monolíticas de padre y madre se multiplican: hablamos de madre biológica y de madre social, de padre biológico y de padre social. Pero estas distinciones resultan, también, cortas. No solo porque la distinción biológico social resulta poco específica - ¿Por qué es más biológico proveer de genes que de alimento? ¿Por qué es más social criar que gestar? (Carsten, 2007) - sino porque no delimitan lo suficiente. Comenzamos entonces a hablar de madre genética y madre gestacional, la primera para referirnos a aquella que aporta el óvulo y la segunda para aquella que lleva adelante la gestación ${ }^{3}$. Y por último de padres y madres de intención, poniendo con estos términos el deseo en el origen de la procreación ${ }^{4}$ y con ello resaltando las figuras de quienes promueven el acto procreativo, aquellas personas de quienes parte la voluntad y el deseo de ser madres y/o madres independientemente de su aportación biológica. Estamos así en un escenario de parentalidades múltiples o pluriparentalidad (Rivas, 2009) que ya no necesariamente comparten entre sí un vínculo de conyugalidad que incluya corresidencia, relaciones sexuales y procreativas.

\footnotetext{
${ }^{2}$ Stolcke nos advierte del curioso deslizamiento que ha ocurrido con este término en cuyo origen se refiere a la fecundación con gametos de otra especie y que en las TRAs con humanos toma el significado de donación de personas ajenas al proyecto parental.

${ }^{3}$ Pero esta distinción también será, probablemente, incompleta pues la posibilidad de manipular las células germinales y de combinar información genética de diferentes personas en un mismo gameto nos augura la necesidad futura de nuevos términos más específicos que padre o madre genética.

${ }^{4}$ Bestard (1998: 206 y ss.) menciona que el deseo de ser padres es aquello que se considera en la reproducción actual lo originariamente natural, ahora que en su fragmentación y exteriorización el proceso procreativo se percibe adulterado. Sin embargo, este deseo en el origen es un deseo de ser padre o madre, un deseo distinto al deseo sexual que está en el origen del modelo procreativo recibido. Sexualidad y procreación aparecen cada vez más distinguidas y desligadas.
} 
PROGENITORES, PROVEEDORES, PROCURADORES: LOS AGENTES DEL PROCESO PROCREATIVO

La fragmentación del proceso y la multiplicación de los agentes que intervienen en él son pues el escenario de la procreación en la era de las tecnologías reproductivas contradiciendo, inquiriendo, interpelando, desafiando -casi podríamos decir-el modelo procreativo recibido.

Frente a los proveedores de materiales reproductivos o de gestación, los donantes, están los destinatarios de estas donaciones, los progenitores. Pero a ello debemos añadir los procuradores, es decir los intermediarios, tanto profesionales biomédicos como también "brokers" de los mercados reproductivos, gestores de la oferta y de la demanda de un mercado global cruzado por diversas situaciones socioeconómicas, legislativas, técnicocientíficas y culturales. Sin embargo, algunos estudios muestran que la distinción entre proveedores y procuradores o entre progenitores y procuradores 0 , incluso, entre progenitores y proveedores no son siempre nítidas. Así una misma persona puede ser simultáneamente o en diferentes momentos proveedora y procuradora -donantes que captan nuevos donantes o que optan por crear sus propias agencias de intermediación, como ha ocurrido en el caso de la subrogación-; progenitora y procuradora - personas que desde la experiencia que les ha dado su proceso reproductivo se convierten ellos mismos en mediadores para otros que van a transitar el mismo proceso-; o progenitora y proveedora -donantes de óvulos que mediante su donación pueden sufragar las técnicas reproductivas a las que van a someterse-.

Hace ya tres décadas Francoise Héritier se fijaba en las nuevas tecnologías y auguraba que nada había de nuevo en las tecnologías reproductivas que fuera a alterar el esquema básico de la reproducción humana. Venía a decir que todas las opciones que estas técnicas abrian se asemejaban a formas que, en la diversidad cultural de la gestión de la reproducción humana, unos $u$ otros pueblos de la tierra ya habían practicado (Héritier-Augé, 1988). Parecería que en este caso Héritier erró en su predicción. Las nuevas tecnologías reproductivas han abierto vías y modos de acceso a la parentalidad que resultaban insospechadas. Han promovido debates que las sociedades no se habían planteado y han generado situaciones sociales para las que no disponemos herramientas de gestión. En su desarrollo han instado a la creación de consejos consultores y leyes que siempre parecen destinadas a ser perecederas y han generado la sensación de que aún 
quedan nuevas ventanas que se van a abrir. Charis Thompson (2005) acuñó el término "coreografías" para referirse a las combinaciones, las nuevas relaciones, las situaciones sorpresivas por momentos que se deducen de la puesta en relación de los diferentes agentes en los procesos reproductivos mediante tecnologías biomédicas de las sociedades contemporáneas. No es poco el éxito de este concepto por su capacidad de reflejar la diversidad de situaciones potenciales a juzgar por su uso en las bibliografías, incluidas las de este monográfico. Los artículos y reseñas que se recogen en Procreación asistida con donantes. Entre disputas y redefiniciones de vínculos e identidades de este número Papeles del CEIC son ejemplo de lo acertado de este término para referirse a lo que acontece en estas circunstancias, que ponen en relación material biológico y vínculos de parentesco en el mercado global de tecnologías reproductivas.

\section{Muestra de COREOgRafíAs}

En este monográfico se recogen algunas de las situaciones, circunstancias y relaciones a las que ha dado lugar el desarrollo de las tecnologías reproductivas con donante aplicadas a seres humanos. Son unos pocos casos que dan cuenta de la ampliación del campo de investigación, análisis y reflexión que promueve esta nueva realidad. Es muestra también de las maneras en que las nuevas circunstancias han reabierto y redefinido los parámetros de temas de las ciencias sociales clásicos en torno a parentesco, familia, persona, conocimiento o tecnología. Este especial de papeles del CEIC consta de seis artículos ${ }^{5}$ que recogen diversos estudios de caso: tanto los textos de Consuelo Álvarez e Ignacio Pichardo sobre donantes y donación de semen, situado en Dinamarca, como el de Mariana Viera, sobre donación de óvulos y semen en Uruguay, nos hablan de donantes pero también del papel protagonista de los agentes que actúan como seleccionadores de donantes deseables y adecuados. Rosa María Frasquet Aira (2018) y Mercè Falguera (2018) hablan desde la voz de las

\footnotetext{
${ }^{5}$ En el inicio de este monográfico está el simposium "Nuevas fronteras en la donación reproductiva: gametos, embriones y gestantes. Dinámicas de altruismo e interés en las nuevas configuraciones de parentesco en la era de las tecnologías reproductivas" que organicé y coordiné junto con Consuelo Álvarez Plaza en el XIV Congreso Antropología de la FAAEE (Valencia, septiembre de 2017). Quiero agradecer a todas las personas su participación y aportaciones a aquel simposium, tanto a las que publican aqui su trabajo como a las que por diversas razones no hayan podido participar en él, así como mostrar mi agradecimiento a Consuelo Álvarez por su buen hacer, su compañerismo y su compromiso en aquel trabajo que hizo del simposium no solo un ejercicio fructífero sino también un agradable espacio de intercambio entre colegas.
} 
madres de intención -madres solas por elección en el primer caso; madres lesbianas en pareja en el segundo- recogiendo sus vivencias y sus puntos de vista respecto a la elección de las técnicas reproductivas utilizadas y en cuanto a la relación deseada o deseable con los donantes. El artículo de Rosana Machin, María Helena O. Augusto y Douglas Mendosa muestra un caso que incide en la dimensión global del mercado reproductivo mostrando que éste toma en ocasiones direcciones que podríamos considerar insólitas. El artículo trata de los desplazamientos reproductivos entre Angola y Brasil, es decir, muestra un mercado sur-sur que rompe con el estereotipo del mercado reproductivo que surte desde los países del sur las carencias reproductivas del norte. Por último, Anna María Morero Beltrán también trata sobre los padres de intención, haciendo un interesante avance de una investigación en curso que nos habla de perfiles y preferencias de las personas que en España recurren a embarazos subrogados en el extranjero, un universo que a falta de datos oficiales o fiables desconocemos ampliamente ${ }^{6}$. Este monográfico es también la oportunidad de reeditar un texto de Verena Stolcke que, publicado hace treinta años, se ha convertido en un texto fundamental no solo debido a su carácter de pionero en el abordaje de las tecnologías reproductivas en humanos en la antropología sino también por la vigencia de sus planteamientos. Por otra parte, se suman dos reseñas: la reseña del libro de Ekis Ekman Kajsa El ser y la mercancía. Prostitución, vientres de alquiler y disociación realizada por Susana Rostagnol y la reseña del film documental Aria de Émilie Jouvet realizada por Elixabete Imaz que contribuyen a ampliar el abanico de casos y perspectivas aquí abordadas.

Cada aportación del monográfico tiene múltiples lecturas y cada uno o una de los lectores encontrará los elementos que resulten más sugestivos y pertinentes a sus intereses. Pero en esta introducción me gustaría reseñar estos trabajos desde tres ejes, que, considero, son transversales a la mayoria de las contribuciones que están realizándose en torno a este tema de investigación y que están también aquí: primero, los criterios de deseabilidad y elegibilidad de los donantes; segundo, el debate respecto al mantenimiento o el desvelamiento del anonimato y sus implicaciones en

\footnotetext{
${ }^{6}$ No hay que olvidar que en España se carece de datos fiables de usos de técnicas reproductivas, de usuarios y de donantes, a pesar de que - tal y como apuntan Álvarez y Pichardo (2018) - la ley de reproducción asistida recoge la necesidad de crear una base de datos nacional de donantes.
} 
relación a los agentes intervinientes; y, por último, el carácter estratificado y global del mercado reproductivo.

\section{LOS CRITERIOS DE DESEABILIDAD Y ELIGIBILIDAD DE LOS DONANTES}

Casi todas las sociedades han ejercido algún tipo de control reproductivo y en ese sentido las nuevas tecnologías reproductivas son una parte de lo que Paola Tabet (1985) llamó la "gestión social de la reproducción" en las sociedades contemporáneas. Tras el monopolio que la medicina adquiere en la gestión del embarazo, parto y crianza (Ehrenreich, y English, 1981), el protagonismo de la medicina en la concepción se intensifica. Verena Stolcke (2018) destaca la transferencia de embriones y, más delante, la clonación como hitos de la manipulación del proceso procreativo, lo que junto a externalizar la concepción introduce cierta distorsión -no buscada- en la concepción de la familia, la paternidad y la maternidad ${ }^{7}$. Nos muestra también la connivencia entre técnicas reproductivas y proyectos eugenésicos: el desarrollo de estas técnicas, que se justifican en gran medida porque alivian la infertilidad, va de la mano de la preocupación por la baja natalidad en los paises de Occidente mientras estos mismos países promocionan campañas de esterilización involuntaria de las mujeres en el tercer mundo con el argumento de que el incremento desmedido de la natalidad asfixia el desarrollo de los mismos.

Estos escenarios, si bien explícitamente contienen la promesa de que la manipulación es una forma de mejorar la salud individual y general de la población, promueven y contienen a su vez aspectos eugenésicos y a menudo claramente racistas. El trabajo de Mariana Viera (2018) es especialmente esclarecedor de la potencial orientación racista de las tecnologías reproductivas que se camufla en el "natural" deseo de los padres de intención de que sus hijos tengan similar aspecto fenotípico al propio, lo que excluye como donantes a aquellas personas que no acuerden con la apariencia física (o autopercepción física) individual o grupal de los demandantes. De ahí la pertinencia del énfasis de Viera en la percepción fenotípica que de sí mismos tienen los ciudadanos uruguayos como mayoritariamente descendientes de europeos, lo que hace que algunos grupos sociales sean descartados en cuanto donantes en la medida en que no son "representativos" de las características fenotípicas

\footnotetext{
${ }^{7}$ Remitimos al artículo de Stolcke (2018) para una pequeña historia de esta intervención en la concepción desde la medicina.
} 
del país. Además la estructura de clases, que se solapa con la estratificación racial, hace que solo se perciban como reproducibles/deseables donantes provenientes de determinados grupos de la población: en la medida en que las clases medias (autopercibidas) como europeas son las que demandan servicios de procreación asistida, solo los donantes que responden a esta similitud se perciben como deseables.

Sin embargo, en ocasiones la selección eugenésica no se detiene en estos rasgos fenotípicos paradigmáticos de la raza, como es el color (de piel, de pelo, de ojos), sino que adquiere matices más sutiles; así Viera habla de que son descartados los potenciales donantes calvos y, en el artículo de Álvarez y Pichardo (2018), donde el representante del banco de semen nos confirma que los más bajos de 1'75 metros son descartados como donantes porque, simplemente, los rasgos de calvicie y de estatura baja no son deseables por nadie.

A esta demanda fenotípica que hace que determinados donantes sean desechados de antemano porque no coinciden con la demanda de similaridad o idoneidad requerida por los padres de intención, debe sumarse el coste de producción - podríamos denominar- del donante que se considera desde los intermediarios. Tanto en el artículo de Álvarez y Pichardo como en el de Viera se destaca que a la persona donante se le pide constancia, contención sexual, hábitos saludables y comprensión de los procedimientos, algo que se considera que no todos los segmentos sociales pueden garantizar - de ahí la preferencia por universitarios en la donación- y que redunda de nuevo en el solapamiento de clase y raza, donde algunos segmentos quedan descartados de antemano como deseables.

Un elemento importante es que en este proceso los medico-científicos se erigen en los principales agentes que deciden respecto a la deseabilidad, aplicando para ello criterios de viabilidad económica, evaluación de la capacidad de los individuos para responder a las exigencias que el procedimiento de donación impone y erigiéndose en vehiculizadores de las preferencias de los usuarios, siendo ellos los que en último término determinan quién es o no elegible, dejándose llevar para ello por criterios que, en ocasiones, tienen como único sustento el "sentido común" —“¿Lo usaría para mí?" se pregunta respecto a la selección de los donantes un técnico entrevistado por Viera (2018)—. 
Si los mediadores médicos buscan determinadas cualidades que hacen que la persona donante sea más fiable, comprometida y rentable, en los casos en los que las y los progenitores eligen al o a la donante otros rasgos pueden cobrar importancia: así la religión, los niveles de estudios, la familia de origen o los gustos y aficiones del o de la donante pueden resultar determinantes en la selección -como por ejemplo, el donante que fue seleccionado por su gusto por las ballenas que se menciona en Álvarez y Pichardo (2018)-, lo que presume la "genetización" de determinados rasgos sociales, es decir, que a la postre se atribuye a determinados rasgos la potencialidad de la transmisión genética que justificaría la elección realizada.

\section{DONACIÓN, ANONIMATO E IDENTIDAD}

La cuestión del anonimato de la donación y del donante en la aplicación de las técnicas reproductivas se ha convertido en una cuestión que ocupa a juristas, académicos, y también a procuradores —profesionales médicos especialmente- y padres y madres concernidos. Otras voces, en cambio, como las de las y los donantes, así como las de los propios nacidos y nacidas por estas técnicas, se observan ausentes ${ }^{8}$.

En las posturas favorables al levantamiento del anonimato tanto como entre las que defienden mantenerlo, el interés superior del menor parece regir el debate, aunque este interés puede ser interpretado de maneras diversas. El principio del anonimato del donante fue generalizado en las primeras regulaciones de la donación reproductiva. El anonimato del donante - que se vinculaba a la renuncia al establecimiento de vínculo de filiación - ha sido lo habitual en relación a la donación de semen en Europa, en la que se siguió un modelo de donación que se inspiraba en la donación de sangre (Thèry, 2007). La idea de la paz familiar y respeto a las decisiones de los padres de intención eran los argumentos en las que se apoyaba el anonimato, junto con la defensa del derecho a la intimidad tanto de las familias mismas como de los donantes. En el fondo, el fantasma de un progenitor biológico que compitiese con el padre social era un elemento siempre presente. También otras cuestiones, como la presunción de que la ruptura del anonimato redundaría en una reducción

\footnotetext{
${ }^{8}$ En el caso de estos últimos entre otras cuestiones porque solo desde hace poco estos tratamientos tienen una aplicación y expansión amplia y no han tenido oportunidad de visibilizarse.
} 
de los donantes disponibles - pues muchos de ellos serían reacios a donar sabiendo que en el futuro su identidad podría ser desvelada- también han tenido peso en la prevalencia del anonimato.

Sin embargo, las posturas que abogan por el derecho a conocer del nacido de estas técnicas han cobrado fuerza en los últimos años. Se argumenta que es una información relativa a sus personas que podría llegar a ser valiosa en cuestiones como la de la salud, pero también - o tal vez sobre todo- se mantiene que esta "revelación de los orígenes" es un componente esencial en la construcción de la propia identidad del individuo. El reconocimiento del derecho a la identidad en la declaración de los derechos del niño y las modificaciones en las leyes de adopción de los últimos años han tenido probablemente repercusión en estas posiciones en las que se atribuye a los nacidos con participación de donantes un deseo o/y una necesidad potencial de "conocer" los orígenes que debería ser atendida.

De esta forma, en las últimas décadas en algunos países europeos se observa una tendencia a romper con el principio del anonimato en beneficio del nacido una vez alcanzada cierta edad (Alkorta Idiakez y Farnós Amorós, 2017). Este revelamiento tendría diversos grados que iría desde que el nacido por TRAs conozca sus circunstancias de nacimiento y datos no identificativos del o de la(s) donante(s), hasta el acceso a datos identificativos y la supresión total del anonimato, pudiendo el nacido mediante las TRAs conocer la identidad e incluso contactar con la persona donante, sin que ello comporte vínculo de filiación o de otro tipo?.

Respecto a los agentes intervinientes en esta cuestión no se puede decir que las posturas sean unánimes y se perciben diversos puntos de vista, que más allá de principios más o menos individuales o valores culturales locales responden también a las posiciones de los sujetos concernidos ${ }^{10}$. Así en relación a las y los progenitores, es constatable que la perspectiva respecto al anonimato varía en relación a la formación familiar y en función del tipo de donación, produciéndose una correlación entre el modelo familiar y la posición respecto al anonimato según se perciba este conocimiento como

\footnotetext{
${ }^{9}$ Véase una detallada revisión por países en Alkorta Idiakez y Farnós Amorós, 2017.

${ }^{10}$ Debe insistirse también en la ausencia de un conocimiento profundo de las opiniones respecto a esta cuestión dado que los estudios realizados en torno al tema están sesgados precisamente por la mayor participación de personas cuya posición favorable al levantamiento del anonimato quiere ser visibilizada (Jociles, 2016: 26).
} 
una amenaza o por el contrario un apoyo a la construcción de un relato familiar (Jociles, ed., 2016). Así, mientras que las familias biparentales heterosexuales parecen más proclives a mantener el anonimato incluso ocultando en secreto la forma de concepción, otros modelos familiares son más tendentes a posicionarse a favor de dar acceso a conocer datos no identificativos del donante pero sin que esto suponga dotar de una identidad al donante -por ejemplo en el caso de parejas de mujeres lesbianas con donante (Imaz, 2017a: 442)-, pasando por otros en los que el donante adquiere un protagonismo notable en la construcción del relato familiar - como en el caso de las madres solas por elección que describen Jociles y Rivas (2014) en el que el donante se reviste de una identidad pero no llega a ser identificado- o puede incluso participar de la cotidianidad de la familia por medio de comunicaciones regulares -como ocurre a menudo con las gestantes en el caso de familias homoparentales masculinas que han recurrido a subrogación en estados Unidos, que menciona Gross (2012: 195 y ss.)-.

Por una parte, el derecho a conocer del nacido y el correlato del levantamiento del anonimato puede contener la suposición de que la genética es un componente esencial de la identidad. Sin embargo, señala Thèry (2007: 92), el anonimato deja al individuo sin opciones de remontar la historia de su vida más allá de sí mismo. Ella niega que este argumento implique una genetización de la identidad, sino más bien resituar el origen de esa persona en una acción compleja de múltiples participantes (ibídem: 93). Los gametos anonimizados convertidos en pura materia reproductiva sitúan el momento de la concepción en un punto cero, a partir del cual los médicos no transmiten sino que dan la vida a partir de un material reproductivo apropiado y sustraído del elemento relacional que constituye a las personas. Independientemente de que el donante - tanto como el nacido- pueda o no querer dotar de un significado transcendente a sus gametos -en el presente o en el futuro-, Théry insiste en que la particularidad del don (o venta) de facultades biológicas y capital genético que conlleva la procreación asistida está no solo en el valor que socialmente se le está otorgando al componente biogenético, sino también en la naturaleza relacional de la persona -es decir, que toda persona nace de una relación de relaciones-.

Thèry habla de que la anonimización del don hace desaparecer al donante de la escena y todo ocurre como si la institución medica fuera la 
propietaria de ese material despersonalizado. Desde la perspectiva del nacido pero también del donante, esta idea es interesante porque plantea no tanto un necesario componente genético de la identidad sino más bien el derecho del donante a no ser utilizado como un instrumento y despojado del carácter de persona. Bajo este prisma, los debates sobre el anonimato adquieren la perspectiva de una demanda de la recuperación de la relación social de la donación y una consideración conjunta de las prerrogativas que deben ser consideradas en el binomio donante y nacido de la donación.

\section{EL CARÁCTER ESTRATIFICADO Y GLOBAL DEL MERCADO REPRODUCTIVO}

Los apartados anteriores muestran que en el escenario dibujado por las nuevas tecnologías reproductivas existen desigualdades locales basadas en género, clase, raza y jerarquías étnicas que se evidencian en la constatación de quiénes donan, quiénes seleccionan a los y las donantes y quiénes acceden a la donación, lo que visibiliza estructuras de desigualdad. Pero esta desigualdad no se limita al interior de cada comunidad, país o región sino también tiene una dimensión en el ámbito transnacional en la que la inequidad de recursos convierte a algunos grupos en potenciales consumidores de servicios y materiales reproductivos y a otros en proveedores (Ikemoto, 2009: 277). Esto lleva a ampliar la noción de "reproducción estratificada" acuñada por Colen (1995) referida a la división de tareas reproductivas en base a desigualdades - de clase, de raza, étnicas... - también al ámbito específico de la procreación. Pero en esta dimensión trasnacional las diferencias entre regiones no se limitan ni pueden reducirse a los desequilibrios norte-sur, sino que aparecen otras variables como el avance científico, el desarrollo legislativo, los valores morales, familiares y de género, y otras, a partir de las cuales algunas regiones se especializan en proveer $u$ ofrecer algunos tipos de servicios reproductivos.

El artículo de Anna María Morero Beltrán (2018) sobre el perfil de las personas españolas que recurren a la maternidad subrogada sirve de ejemplo de la complejidad de variables que actúan en la conformación del mapa global de la reproducción asistida. Si bien España prohíbe los contratos de gestación subrogada y no considera válido ningún acuerdo de estas características que se realice en su territorio nacional, sí que accede a nacionalizar y regularizar la situación de los bebés que nazcan en países terceros donde estas prácticas sean legales (Imaz, 2017b). Así, los padres 
y/o madres de intención se desplazan a diferentes países no solo en función de los recursos económicos de los que disponen sino también de las propias legislaciones y regulaciones de la materia en el país receptor respecto al tipo de intervenciones ofrecidas, las características personales, el tipo de familia y orientación sexual de los candidatos, así como en función de los valores, criterios y garantías que consideran que deben regir el proceso (Gross, 2012). El trabajo de Consuelo Álvarez e Ignacio Pichardo (2018) hace hincapié en la especialización danesa como proveedora de gametos masculinos mientras que la reseña sobre el documental Aida (2016) de Émilie Jouvet pone en evidencia la especialización en inseminaciones artificiales y en fecundaciones in Vitro para parejas de mujeres y mujeres solas de Bélgica y España. La complejidad de relaciones y variables que actúan en este mapa de la reproducción no es óbice para definirlo como una industria, en la que las perspectivas que remarcan la desigualdad, la mercantilización y la explotación, como lo hace Kajsa Erik (2017) —véase la reseña de Susana Rostagnol en este monográficocuentan con elementos firmes para sustentarla. Una industria de la (in)fertilidad y de la (in)fecundidad que tal y como afirma Ikemoto es "sofisticada en algunos aspectos y cruda en otros" y en la que se "mezclan familia y comercio en muy diferentes maneras" (2009: 278).

Por todo ello la movilidad reproductiva responde a una compleja mezcla de razones: el coste de los tratamientos aunque importante y fundamental, es solo una de ellas. Así, las características del ordenamiento jurídico y las leyes más abiertas, la disponibilidad de gametos o gestantes, o que el catálogo de donantes responda a determinadas características se unen al desarrollo tecnológico, las garantías jurídicas, las facilidades de ingreso y estancia en el país, los roles sociales y de género, o simplemente la garantía de secreto que la distancia respecto al país de origen son también importantes. El artículo de Rosana Machin et al. (2018) que habla de las parejas angoleñas trasladadas a Brasil en busca de tecnologías reproductivas $y$, a menudo, donación de gametos es un buen ejemplo de las coreografías procreativas (Thompson, 2005). Desde Angola, que padece tasas de infertilidad inusuales y un estigma fuerte sobre las personas sin hijos, parejas $y$, especialmente, mujeres acuden a Brasil por largos periodos en busca de tratamientos que resuelvan su infertilidad. En Brasil encuentran una industria de la reproducción desarrollada, un catálogo de gametos provenientes de personas fenotípicamente afines, una lengua común y una comunidad angoleña emigrada que los acoge, así como la 
garantía de preservación del secreto de los tratamientos que en este país se están llevando a cabo. Si bien el desembolso económico del tratamiento puede ser gravoso, prolongar la estancia en Brasil hasta más allá del parto garantiza a muchas de estas mujeres una atención prenatal y perinatal adecuada y gratuita, aquella a la que tienen acceso en la sanidad pública brasileña en virtud de su residencia temporal y a la que en su país muchas de las familias no podrían acceder.

"Turismo reproductivo" es el apelativo que a menudo, incluido en el mundo académico, se le ha dado a esta circulación de personas con objetivos reproductivos. La reseña dedicada por Elixabete Imaz al documental de Émilie Jouvet Aida (2016) muestra una perspectiva crítica respecto al uso de este término. Turismo es un término lúdico que oculta la complejidad de relaciones que se establecen en esta reproducción globalizada. Frente a este término, Jouvet propone el término "asilados procreativos", remarcando que el no reconocimiento de algunos derechos obliga a las personas a viajar a terceros países en busca de tratamientos, lo que en no pocas ocasiones, lejos del hedonismo que traslada el término turismo, acarrea serias dificultades y sufrimientos de diversos niveles para los concernidos y concernidas.

Encontramos de esta forma países proveedores de determinados servicios, especializados en determinado tipo de donantes y/o técnicas, sea por su legislación o por su desarrollo tecnológico, por sus tarifas y costes bajos, por la accesibilidad a las técnicas vetadas en otros lugares o por garantías de anonimato, cuyos ciudadanos y ciudadanas, a su vez, viajan a terceros países en busca de otros servicios que son inaccesibles en el propio. Se trata en definitiva de un mercado multilateral y complejo, en el que las direcciones de los servicios ofertados, las materias reproductivas disponibles y los demandantes de fertilidad/fecundidad que acceden a ellos son múltiples.

\section{LAS TÉCNICAS DE REPRODUCCIÓN ASISTIDA Y EL DEBATE SOBRE LOS DERECHOS REPRODUCTIVOS}

Mari Luz Esteban (2001) distinguió entre las viejas tecnologías reproductivas y las nuevas tecnologías reproductivas. Las primeras se referian a los medios anticonceptivos y aborto, separaban sexualidad y reproducción y garantizaban la posibilidad de sexualidad sin reproducción. Las nuevas tecnologías, por su parte, también distinguían a la sexualidad 
de la reproducción pero en este caso posibilitaban la reproducción sin intermediación de la sexualidad. Mientras las primeras evitan la fecundidad, las segundas la promueven superando los problemas impuestos por la infertilidad o la imposibilidad de fecundación. Lo útil de la distinción es que al denominarlas de esta forma, Esteban remarca que se trata de dos caras de la misma dinámica: la de intervenir, controlar y gestionar la procreación humana que en las sociedades contemporáneas se caracteriza por hacerlo desde la aplicación del conocimiento biotecnológico y desde el protagonismo del sistema médico-científico.

Ignorando lo sensible de los componentes que están interactuando en este campo - cuerpos y familias, capacidades y deseos reproductivos, identidades raciales, étnicas y nacionales, subjetividades sexuales y de género, intereses mercantiles y desarrollo de industrias biotecnológicas... que en una $u$ otra de sus dimensiones aparecen en los textos que componen este número- el debate sobre la reproducción globalizada se enmarca en una buena parte en la concepción de la reproducción como un ámbito del consumo en la que se entiende que tanto personas proveedoras, intermediarias como usuarias, desde la autonomía y la responsabilidad, se encuentran en un espacio entre iguales. El consumidor elige libremente frente a una oferta también libre desde la responsabilidad ante las elecciones hechas en un mercado. Es así que términos como el turismo reproductivo se han acuñado.

Solinger (2001) ya advertía de las claras desventajas que lo que ella denomino "la ideología de la elección" aplicada al ámbito de la reproducción contiene para muchas mujeres - véase la reseña de Imaz en este monográfico- La libertad de elegir respecto a la reproducción que el feminismo ondea desde hace décadas se refería al respeto a las preferencias personales de las mujeres en cuanto a ser madre o no, la posibilidad de acceder al aborto y a la anticoncepción, a las relaciones sexuales libres y a acabar con la coerción reproductiva. Pero la otra cara de la ideología de la elección es la condición de ejercerla de forma responsable, lo que amenaza con convertir la maternidad en un privilegio de clase pues solo las personas cualificadas para ello y con suficientes recursos - no solo económicos, sino también materiales, culturales, formativos y de estatus adecuados- podrían entrar en el "mercado reproductivo" en condiciones adecuadas o socialmente requeridas (ibídem: 224). Frente a ello, Solinger aboga por retornar el debate sobre la 
reproducción al ámbito de los derechos, algo de lo que las personas son "titulares" independientemente de sus recursos (ibídem: 223).

Desde la atalaya que nos procura la argumentación de Solinger es constatable como cuando nos referimos al ámbito de la reproducción asistida, los derechos a los que se alude omiten a la reproducción misma. Tal y como se mencionaba más arriba, al hablar de las tecnologías reproductivas se habla del derecho del menor, del derecho a la intimidad, del derecho a la familia o del derecho a la identidad. Pero paradójicamente, y tratándose del ámbito de la procreación es llamativo, en muy pocos casos se habla de derechos reproductivos.

En la aún balbuceante definición de los derechos reproductivos se menciona "el reconocimiento del derecho básico de todas las parejas e individuos a decidir libre y responsablemente el número de hijos, el espaciamiento de los nacimientos y a disponer de la información y de los medios para ello, así como el derecho a alcanzar el nivel más elevado de salud sexual y reproductiva." 11 . En su formulación se percibe que estos derechos se dirigen, fundamentalmente, a garantizar la "capacidad de decidir" en el sentido de restringir o espaciar la fecundidad, orientación en la que se adivina la presión ejercida por el movimiento feminista. En este sentido, en su desarrollo actual, los derechos reproductivos adquieren "solo"la acepción de limitar y separar los nacimientos de los hijos y de desterrar la coerción que obligue a las mujeres a la reproducción. Sin embargo, tal y como proponía Paola Tabet (1985) no podemos entender la gestión social de la reproducción solo en el sentido restrictivo de limitarla sino que es algo que siempre es gestionado por las sociedades también para favorecerla y adaptarla a las normas sociales. Dicho en otras palabras, no existe una fecundidad natural; las sociedades establecen mecanismos tanto permanentes como puntuales para que la fecundidad se produzca y se produzca según las pautas establecidas por ellas. El espacio de los derechos reproductivos abarca, en consecuencia, todo el espectro de cuestiones que tienen que ver con la gestión social de la reproducción.

En su aplicación, las técnicas reproductivas plantean nuevas preguntas en el ámbito reproductivo que tienen que ver con el acceso a esas técnicas de personas infecundas por razones de infertilidad $u$ otras (como las opciones

\footnotetext{
${ }^{11}$ Programa de Acción de la Conferencia Internacional sobre Población y Desarrollo, El Cairo, Egipto, 5-13 de septiembre, 1994, Doc. de la ONU A/CONF.171/13/Rev.1 (1995).
} 
sexuales o de estilo de vida), los derechos de las personas que nacen de los usos de estas tecnologías así como los derechos de las personas que venden o donan sus capacidades fértiles para la fecundidad de otras personas. Los debates sobre estas cuestiones son todavía parciales y embrionarios. El exponencial desarrollo y expansión de las tecnologías reproductivas ha abierto un campo nuevo sobre los derechos en el ámbito reproductivo que está aún sin recorrer. Los textos que componen este monográfico, desde la particularidad de cada uno de los casos que muestran, son también contribuciones a ese enorme ámbito de reflexión que está aún en desarrollo.

\section{BIBLIOGRAFÍA}

Alkorta, I., y Farnos, E. (2017). Anonimato del donante y derecho a icconocer:un difícil equilibrio. Oñati Socio-legal Series,7(1), 148-178.

Álvarez Plaza, C., y Pichardo Galán, J. I. (2018). La construcción del "buen donante" de semen: selección, elección, anonimato y trazabilidad. Papeles del CEIC. International Journal on Collective Identity Research, 2018/2(194).

Bestard, J. (1998). Parentesco y modernidad. Barcelona: Paidós Ibérica.

Carsten, J. (2007). La sustancia del parentesco y el calor del hogar: alimentación, condición de persona y modos de vinculación entre los Malayos de Palau Langkiwi. En R. Parkin y L. Stone (Eds.), Antropología del parentesco y de la familia (pp. 515-542). Madrid: Editorial Universitaria Ramón Areces.

Colen, S. (1995). Like a mother to them: Stratified Reproduction and West Indian Childcare Workers and Employers in New York. En F. Ginsburg, y R. Rapp (Eds.), Conceiving the New World Order: The Global Politics of Reproduction (pp. 78-102). Berkeley-Los Angeles-Londres: University California Press.

Davis-Floyd, R. E. (1993). The technocratic model of birth. En S. T. Hollis, L. Pershing y M. J. Young (Eds.), Feminist theory and the study of Folklore (pp. 297-326). Urbana/Chicago: University of Illinois Press.

Ehrenreich, B., y English, D. (1981). Brujas, comadronas y enfermeras. Historia de las sanadoras. Barcelona: LaSal-Cuadernos inacabados.

Ekis, E. K. (2017). El ser y la mercancía. Prostitución, vientres de alquiler y disociación. Barcelona: Bellaterra.

Esteban, M. L. (2001). Re-producción del cuerpo femenino. Discursos y prácticas acerca de la salud. Donostia: Gakoa liburuak. 
Falguera, M. (2018). Deseos, semen y bebés. Técnicas reproductivas y comaternidades lésbicas. Papeles del CEIC. International Journal on Collective Identity Research, 2018/2(196).

Frasquet Aira, R. M. (2018). Elecciones reproductivas, anonimato y parentesco: discursos, estrategias e implicaciones para las 'Madres Solteras por Elección'. Papeles del CEIC. International Journal on Collective Identity Research, 2018/2(197).

Gross, M. (2012). Choisir la maternité gay. Toulouse: Éditions Érès.

Héritier-Augé, F. (1985). La Cuisse de Jupiter, Réflexions sur les nouveaux modes de procréation. L'Homme, 94(2), 5-22.

Imaz, E. (2017a). La maternité partagée chez les couples de lesbiennes. Ethnologie française, 2017/3(167), 437-446.

Imaz, E. (2017b). Same-sex parenting, assisted reproduction and gender asymmetry: Reflecting on the differential effects of legislation on gay and lesbian family formation in Spain. Reproductive Biomedicine $\epsilon$ Society Online, 4, 5-12.

Ikemoto, L. (2009). Reproductive tourism: equality concerns in the global market for fertility services. Law $\in$ Inequality: A journal of Theory and Practice, 27(2), 277-309.

Jociles, M. I. (Ed.). (2016). Revelaciones, filiaciones y biotecnologías. Una etnografía de la comunicación de los origenes a los hijos e hijas concebidos mediante donación reproductiva. Barcelona: Bellaterra.

Jociles, M., y Rivas, A. M. (2014). Narrativas sobre los orígenes y formación familiar de los hijos/as de MSPE que han concebido mediante donación de semen. En M. F. Moscoso (Dir.) Etnografía de la socialización en las familias (pp. 57-69). Madrid: Traficantes de sueños.

Lebrun, A., y Burguière, A. (1988). El cura, el príncipe y la familia. En A. Burguière et al. (Eds.), Historia de la Familia 2: El impacto de la modernidad (pp. 97-160). Madrid: Alianza.

Machin, R., Augusto, M. H. O., y Mendosa, D. (2018). Cross-border reproduction: the reproductive market in Angola and Brazil. Papeles del CEIC. International Journal on Collective Identity Research, 2018/2(198).

Marco, E. M. (2004). La maternidad como objeto de estudio de la Historia Social. Debate Historiográfico sobre el proceso de profesionalización de la maternidad en los orígenes de los Estados de Bienestar. En M. I. 
del Val. et al. (Coords.), La Historia de las Mujeres: Una revisión Historiográfica (pp. 277-294). Valladolid: Universidad de Valladolid.

Morero Beltrán, A. M. (2018). Características de las familias creadas por gestación subrogada en el Estado español. Papeles del CEIC. International Journal on Collective Identity Research, 2018/2(199).

Palacio Lis, I. (2003). Mujeres ignorantes: madres culpables. Adoctrinamiento y divulgación materno-infantil en la primera mitad del siglo XX. Valencia: Universitat de València.

Parsons, T. (1966). La estructura social de la familia. En E. Fromm et al. (Eds.), La familia (pp. 31-64). Barcelona: Península.

Rivas, A. M. (2009). Pluriparentalidades y parentescos electivos. Presentación volumen monográfico. Revista de Antropología Social, 18, 7-19.

Schneider, D. (1980). American Kinship. A cultural Account. Chicago: The University of Chicago Press.

Segalen, M. (1988). La revolución industrial: del proletariado al burgués. En A. Burguière et al. (Eds.) Historia de la Familia 2: El impacto de la modernidad (pp. 387-424). Madrid: Alianza.

Solinger, R. (2002). Beggars and Choosers, How the politics of choice shapes adoption, abortion, and welfare in the United States. Nueva York: Hill and Wang.

Stolcke, V. (2018). Las nuevas tecnologías reproductivas, la vieja paternidad. Papeles del CEIC. International Journal on Collective Identity Research, 2018/2(193).

Tabet, P. (1985). Fertilité naturelle, reproduction forcée. En N. C. Mathieu, L'arraisonnement des femmes. Essais en anthropologie des sexes. Cahiers de l'homme, nouvelle série XXIV (pp. 61-146). Paris: Éditions de l'EHESS.

Thèry, I. (2009). Anonymat des dons d'engendrement. Filiation et identité narrative des enfants en temps du démariage. En E. Porqueres i Gené (Ed.), Défis contemporains de la parenté (pp. 81-106). París: Editions de I'EHESS.

Thompson, C. (2005). Making parents: The ontological choreography of reproductive technologies. Cambridge: Massachusetts Institute of Technology Press.

Uribe, J. M. (2016). Biopolítica del niño sano: procreación biológica, social y jurídica. Quaderns-e de I'Institut Català d'Antropologia, 21(2), 103-118. 
Viera, M. (2018). Marcas de identidad, atributos sociales deseables y fenotipos compartidos. Un análisis a partir de la donación de gametos en Uruguay. Papeles del CEIC. International Journal on Collective Identity Research, 2018/2(195).

Weston, K. (2003). Las familias que elegimos. Lesbianas, gays y parentesco. Barcelona: Edicions Bellaterra. 